\title{
EFEITO DOS COFATORES HIDROQUINONA, PROLINA E TRIPTOFANO NO ENRAIZAMENTO DE MINIESTACAS DE CLONES DE Eucalyptus grandis $\mathrm{x}$ E. urophylla ${ }^{1}$
}

\begin{abstract}
Patrícia Bueno Goulart², Aloísio Xavier³ e José Maria Moreira Dias ${ }^{4}$
RESUMO - Este estudo teve como objetivo avaliar a eficiência dos cofatores hidroquinona, prolina e triptofano, associados ao regulador de crescimento AIB (ácido indolbutírico) na propagação vegetativa pelo enraizamento de miniestacas de quatro clones de Eucalyptus grandis x E. urophylla. As miniestacas foram coletadas no minijardim clonal realizado em sistema de hidroponia em canaletas. O delineamento experimental utilizado foi o inteiramente casualizado, constituído de quatro concentrações para cada cofator e quatro clones, em quatro repetições e parcelas compostas de 16 plantas/repetição. Foram realizadas avaliações na casa de vegetação, casa de sombra e ao sol nas miniestacas enraizadas. Concluiu-se que o triptofano $\left(0,8 \mathrm{mg} \mathrm{L}^{-1}\right)$ e a hidroquinona $\left(0,2 \mathrm{a} 0,4 \mathrm{mg} \mathrm{L}^{-1}\right)$, aplicados associados ao AIB, melhoraram o enraizamento em três clones dos quatro clones avaliados; enquanto a prolina $\left(0,2\right.$ a $\left.0,4 \mathrm{mg} \mathrm{L}^{-1}\right)$, aplicada associada ao AIB, promoveu melhoria expressiva no enraizamento das miniestacas nos quatros clones estudados, evidenciando ser entre os cofatores testados o mais eficiente.
\end{abstract}

Palavras-chave: Miniestaquia, Estaquia, Propagação vegetativa e Silvicultura clonal.

\section{EFFECT OF COFACTORS HYDROQUINONE, PROLINE AND TRYPTOPHANE ON THE ROOTING OF MINI-CUTTINGS OF Eucalyptus grandis $x$ E. urophylla CLONES}

\begin{abstract}
The objective of the present work was to evaluate the efficiency of the hydroquinone, proline and tryptophane cofactors, associated with IBA growth regulator on vegetative propagation by the rooting of mini-cuttings of four clones of Eucalyptus grandis $x \boldsymbol{E}$. urophylla. The mini-cuttings were collected in a mini-clonal hedge grown in a hydroponic system in small gutters. It was used a complete random experimental design, with four replicates and plots of 16 plants per replicate. Evaluations of rooted mini-cuttings were carried out in a greenhouse, in a shade house and in the open sun. It was concluded that the tryptophane $\left(0.80 \mathrm{mg} \mathrm{L}^{-1}\right)$ and hydroquinone $\left(0.20\right.$ to $\left.0.40 \mathrm{mg} \mathrm{L}^{-1}\right)$ used in association to IBA, improved the rooting in three out of four evaluated clones whereas proline $\left(0.20\right.$ to $\left.0.40 \mathrm{mg} \mathrm{L}^{-1}\right)$ associated to IBA improved significantly rooting of the four studied clones, proving to be among the most efficient cofactors.
\end{abstract}

Keywords: Mini-cutting, Stem-cutting rooting, Vegetative propagation and Clonal forestry.

\section{INTRODUÇÃO}

No Brasil, a propagação vegetativa de Eucalyptus passou por várias modificações, tendo início com a técnica da estaquia implementada em escala comercial no final de 1970. Atualmente, é adotada na maioria das empresas florestais brasileiras. Desde o início da sua implementação, os reguladores de crescimento, principalmente as auxinas, sempre estiveram nos trabalhos de propagação, visto a possibilidade de proporcionar

\footnotetext{
${ }^{1}$ Recebido em 19.02.2009 e aceito para publicação em 02.05.2011.

${ }^{2}$ Programa de Pós-Graduação pela Universidade Federal de Viçosa, MG, Brasil. E-mail: <pbgoulart@uol.com.br>.

${ }^{3}$ Departamento de Engenharia Florestal, Universidade Federal de Viçosa, MG, Brasil. E-mail: <xavier@ufv.br>.

${ }^{4}$ Departamento de Fitotecnia,Universidade Federal de Viçosa, MG, Brasil. E-mail: <jmmdias@ufv.br>.
} 
maior porcentagem, velocidade, qualidade e uniformidade de enraizamento, embora a sensibilidade das células vegetais e dos clones seja variável.

As condições fisiológicas da planta doadora de propágulos dependem de um conjunto de fatores intrínsecos, que podem, ou não, estar atuando no metabolismo da planta na ocasião da coleta de estacas (HACKETT, 1987; NORBERTO, 1999). Cada vez mais, acredita-se que há fatores endógenos, além das auxinas, controlando o processo de enraizamento adventício, em que carboidratos, proteínas, aminoácidos, vitaminas, compostos fenólicos e outras substâncias ainda não identificadas contribuem para a iniciação de raízes adventícias, quando combinados em concentrações e proporções adequadas (ONO; RODRIGUES, 1996). No entanto, as auxinas têm apresentado efeitos diretos e significativos no curso desse processo, mas na propagação de Eucalyptus spp. por estaquia o regulador de crescimento de maior uso tem sido o ácido indolbutírico (AIB).

Os monofenóis e, especialmente, os difenóis como a hidroquinona, a prolina e o triptofano têm sido indicados como aqueles que atuam sinergicamente como cofatores de enraizamento. Resultados de pesquisa indicaram que a prolina aumentou a porcentagem de brotos enraizados e o número de raízes por broto em Prumus avium e $P$. cerasus (DUART, 1986, citado por LIMA, 1998). Segundo Kim et al. (1994), citados por Lima (1998), em trabalho com Quercus acutissima geralmente a prolina é utilizada em meios de cultura para indução de embriões somáticos, associada ou não a diferentes combinações de auxinas. Quanto ao triptofano, é comum o seu uso em plantas como constituinte de proteínas e precursor intermediário da biossíntese de várias substâncias indólicas, entre elas o ácido indolacético (AIA) (HAGGQUIST et al., 1988). Segundo alguns autores (GORDON et al., 1961; SCHNEIDER et al., 1974; SHINGH, 1981, citados por DUTRA et al., 2002), os fenóis em oxidação reagem com o triptofano para formar a auxina (AIA).

Assim, diante da atual importância da propagação clonal de Eucalyptus, torna-se justificável o desenvolvimento de pesquisas que busquem avaliar o efeito de cofatores no enraizamento de miniestacas de clones de Eucalyptus grandis x E. urophylla. Dessa forma, este estudo teve como objetivo avaliar o efeito dos cofatores hidroquinona, prolina e triptofano, associados ao regulador de crescimento AIB, na propagação vegetativa pelo enraizamento de miniestacas de quatro clones de Eucalyptus grandis x E. urophylla.

\section{MATERIAL E MÉTODOS}

\subsection{Material experimental}

Foram utilizados quatro clones de Eucalyptus grandis x E. urophylla provenientes da empresa International Paper do Brasil, localizada no Município de Mogi Guaçu, São Paulo. A partir de plantas obtidas pela técnica de miniestaquia, o minijardim clonal foi instalado no Viveiro Experimental desta empresa, coberto e constituído dos quatro clones em estudo.

\subsection{Manejo do minijardim clonal}

Conforme a técnica de miniestaquia (XAVIER et al., 2009; ALFENAS et al., 2009) e, de acordo com os procedimentos de manejo adotados pela empresa, o minijardim clonal foi constituído de minicepas obtidas pelo enraizamento de miniestacas oriundas de brotações de plantas propagadas pelo método da microestaquia. As miniestacas enraizadas, ao atingirem 10 a $12 \mathrm{~cm}$ de altura, tiveram seus ápices podados a de $8 \mathrm{~cm}$, constituindo, assim, as minicepas que forneceram as miniestacas (brotações) para realização do experimento.

O sistema de manejo do minijardim clonal adotado foi o utilizado comercialmente pela empresa e composto por canaletas de alumínio revestidas com fibra de vidro, sobre as quais permaneceram as minicepas, transplantadas em tubetes dispostos em bandejas de isopor cobertas por plástico dupla fase. A irrigação e a nutrição mineral foram efetuadas através do sistema automatizado de fertirrigação por inundação, de maneira que somente o sistema radicular permanecia em contato com a solução nutritiva. A cada uma hora o sistema era acionado, irrigando por 20 minutos, até a água atingir $6 \mathrm{~cm}$ de altura do tubete. Após esse período, a canaleta era esvaziada e a solução nutritiva retornava à caixa de armazenagem da solução, sendo esta trocada a cada sete dias. Diariamente, foram mensurados a condutividade elétrica (Ec) e o pH da solução. Nesse período, a Ec variou de 2,00 a 2,40 mS cm-1 e o $\mathrm{pH}$, de 3,05 a 5,76. Em 500 litros de solução nutritiva, adicionaram-se 20 g de nitrato de amônio, 200 g de nitrato de cálcio, 108 g de sulfato de amônio, 60 g de micronutrientes obtidos pelo produto Quelatec AZ ${ }^{\circledR}$ e 740 g de Phytus Super $K^{\circledR}$. O Quelatec AZ ${ }^{\circledR}$ constitui-se

Revista Árvore, Viçosa-MG, v.35, n.5, p.1017-1026, 2011

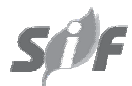


de um quelato solúvel de micronutrientes, composto por ferro, manganês, zinco e cobre na forma quelatada, e por boro e molibdênio na forma mineral. Já o Phytus Super $\mathrm{K}^{\circledR}$ era constituído de um fertilizante composto por NPK (00:40:20).

\subsection{Obtenção, preparo, plantio e enraizamento das miniestacas}

As miniestacas foram coletadas no minijardim clonal e acondicionadas em caixas de PVC transparente, mantidas fechadas. Para conservar as condições de turgescência do material vegetativo, pulverizou-se água com bomba costal, em intervalos de 10 minutos, até a etapa de enraizamento. Então as miniestacas foram preparadas com 5 a $7 \mathrm{~cm}$ de comprimento e com um par de folhas, tendo a área foliar sido reduzida à metade de sua dimensão original.

Após este preparo, as miniestacas foram tratadas com hidroquinona, prolina e triptofano associados à concentração de $500 \mathrm{mg} \mathrm{L}^{-1}$ de AIB (ácido indolbutírico - Merck S.A.) para posteriormente serem transplantadas e colocadas para enraizamento na casa de vegetação climatizada. Foram utilizadas quatro concentrações dos cofatores hidroquinona ( $0 ; 0,1 ; 0,2$ e $\left.0,4 \mathrm{mg} \mathrm{L}^{-1}\right)$, prolina $\left(0 ; 0,1 ; 0,2\right.$ e $\left.0,4 \mathrm{mg} \mathrm{L}^{-1}\right)$ e triptofano (0; 0,2; 0,4 e 0,8 $\left.\mathrm{mg} \mathrm{L}^{-1}\right)$, na formulação líquida, dissolvidos em solução de AIB a $500 \mathrm{mg} \mathrm{L}^{-1}$ (dissolvidos em KOH a $1 \mathrm{~mol} \mathrm{~L}^{-1} \mathrm{e}$ diluídos em água destilada autoclavada). As miniestacas tiveram suas bases $(2 \mathrm{~cm})$ mergulhadas na solução de cofator + AIB por 15 segundos, antes de serem transplantadas no substrato. O período compreendido entre o preparo das miniestacas, seus tratamentos com os cofatores e transplantio no substrato, na casa de vegetação, foi sempre inferior a 30 minutos.

No enraizamento das miniestacas, utilizaram-se como recipientes tubetes plásticos de $55 \mathrm{~cm}^{3}$ de capacidade, contendo substrato constituído de partes iguais de vermiculita de granulometria fina e casca de arroz carbonizada. A nutrição mineral utilizada no substrato foi composta por 4,00 $\mathrm{kg} \mathrm{m}^{-3}$ de Fosmag 500B (MANAH, São Paulo) composto por 4\% de N, 14\% de $\mathrm{P}, 7 \%$ de $\mathrm{K}, 14 \%$ de Ca, $9 \%$ de S, $2 \%$ de $\mathrm{Mg}$ e $0,5 \%$ de B; 5,40 kg m³ de NPK (32:00:03) e 3,06 $\mathrm{kg} \mathrm{m}^{-3}$ de cloreto de $\mathrm{K}$.

O processo de enraizamento das miniestacas foi realizado em casa de vegetação climatizada (umidade relativa do ar $\geq 80 \%$ e temperatura em torno de $27^{\circ} \mathrm{C}$ ), com permanência de 25 dias. Em seguida, as miniestacas foram transferidas para casa de sombra, onde permaneceram por 10 dias para aclimatização e, finalmente, foram colocadas ao sol até completarem 50 dias de idade.

\subsection{Avaliações experimentais}

Foram instalados experimentos independentes, testando-se os diferentes tipos de cofatores (hidroquinona, prolina e triptofano), com delineamento experimental inteiramente casualizado, em arranjo fatorial 4 x 4, constituído de quatro concentrações para cada cofator e quatro clones de Eucalyptus grandis x E. urophylla (H1, H2, H3 e H4), em quatro repetições e parcelas compostas de 16 plantas por repetição.

As avaliações das plantas foram realizadas quanto ao percentual de sobrevivência das miniestacas na saída da casa de vegetação, ao percentual de enraizamento e à altura das miniestacas na saída da casa de sombra. No final do período de exposição a pleno sol, avaliaram-se o percentual de sobrevivência, a altura, o diâmetro de colo e a massa da matéria seca da parte aérea e da raiz das miniestacas enraizadas.

As avaliações de altura, diâmetro de colo, massa da matéria seca da parte aérea e do sistema radicular foram realizadas em quatro miniestacas/repetição selecionadas ao acaso em cada tratamento. Os dados resultantes foram submetidos às análises de variância e regressão, utilizando-se os programas Statistica e Excel.

\section{RESULTADOS E DISCUSSÃO}

\subsection{Eficiência da hidroquinona no enraizamento adventício}

Com base nos resultados da análise de variância das características avaliadas (Tabela 1), observou-se efeito significativo, pelo teste de $\mathrm{F}(\mathrm{P}>0,05)$, da interação “clone x tratamento" em relação apenas a duas das características avaliadas (sobrevivência das miniestacas na saída da casa de vegetação - SOBCV e a massa de matéria seca do sistema radicular - PSR). Houve respostas diferenciadas dos clones em relação ao cofator e aos tratamentos adotados.

Os coeficientes de variação experimental encontrados variaram de 8,3 até 29,0\%, evidenciandose razoável precisão experimental em relação às

Revista Árvore, Viçosa-MG, v.35, n.5, p.1017-1026, 2011 
características estudadas, de acordo com os valores normalmente encontrados na literatura (RIBAS, 1997; WENDLING et al., 2000; TITON, 2001).

Não foram observadas diferenças estatísticas entre os tratamentos dos clones estudados em relação às características de sobrevivência das miniestacas na saída da casa de vegetação, enraizamento na saída da casa de sombra, altura na saída da casa de sombra e a pleno sol, diâmetro de colo e peso de matéria seca da parte aérea e da raiz das plantas a pleno sol (Tabela 1).

Os resultados de sobrevivência das plantas a pleno sol, aos 50 dias de idade (Figura 1), indicaram que o clone $\mathrm{H} 1$ destacou-se dos demais, sendo os melhores resultados obtidos entre 0,2 e $0,4 \mathrm{mg} \mathrm{L}^{-1}$ de hidroquinona. Os clones $\mathrm{H} 2$ e $\mathrm{H} 3$ apresentaram resultados de sobrevivência das plantas a pleno sol semelhantes entre si, com as melhores respostas para a concentração de 0,4 mg L $^{-1}$ de hidroquinona. Para clone H4, a aplicação de hidroquinona não apresentou acréscimos significativos nos índices de sobrevivência das plantas a pleno sol.

A hipótese inicialmente foi a de que a aplicação de hidroquinona associada ao AIB nas miniestacas promovia aumento nos percentuais de enraizamento e de sobrevivência, o que foi confirmado em relação aos clones H1, H2 e H3. Na literatura consultada, no entanto, Lima (1998), trabalhando com plântulas de
Eucalyptus grandis, constatou que a hidroquinona, associada ao AIB, não teve influência sobre o percentual de enraizamento e comprimento da parte aérea das plântulas, porém apresentou efeito benéfico no comprimento de raízes. Já James et al. (1981), citados por Lima (1998), obtiveram resultados positivos com relação à rizogênese de estacas de macieira, utilizando hidroquinona associada ao AIA.

\subsection{Eficiência da prolina no enraizamento adventício}

Com base nos resultados da análise de variância das características avaliadas (Tabela 2), observou-se efeito significativo, pelo teste de F ( $P>0,05)$, da interação “clone x tratamento" sobre a maioria das características avaliadas, indicando respostas diferenciadas dos clones em relação ao cofator e às concentrações testadas. Os coeficientes de variação experimental encontrados variaram de 14,9 até $28,5 \%$, evidenciando-se razoável precisão experimental em relação às características estudadas, de acordo com os valores normalmente encontrados na literatura (RIBAS, 1997; WENDLING et al., 2000; TITON, 2001).

Os clones H1, H3 e H4, de modo geral, apresentaram alto índice de sobrevivência na saída da casa de vegetação (Figura 2), sendo os melhores resultados obtidos com a aplicação de 0,4 $\mathrm{mg} \mathrm{L}^{-1}$ de prolina-100\% de sobrevivência. Resultados mais expressivos foram verificados para o clone H2, que apresentou o maior índice de

Tabela 1 - Resultados da análise de variância das características de sobrevivência das miniestacas na saída da casa de vegetação (SOBCV); do percentual de enraizamento (ENRCS) e altura (ALTCS) das miniestacas na saída da casa de sombra; e da sobrevivência (SOB50), altura (ALT50), diâmetro de colo (DC50) e da massa de matéria seca da parte aérea (PSPA) e do sistema radicular (PSR) das plantas aos 50 dias de idade, em função das concentrações do cofator hidroquinona associado a $500 \mathrm{mg} \mathrm{L}^{-1}$ de AIB, dos quatro clones de Eucalyptus grandis x E. urophylla.

Table 1 - Results of the Analysis of Variance (ANOVA) of characteristics of greenhouse exit survival (CGES); shade house exit mini-cuttings rooting percentage (ENRCS) and height (HCS); survival (SOB50), height (H50), root collar diameter (DC50) and dry mass of the aerial portion (DMAP) and root system (DMR) of the plants at 50 days of age, as a result of different concentrations of hydroquinone cofactor associated with $500 \mathrm{mg} \mathrm{L}^{-1}$ IBA of the four clones of Eucalyptus grandis $\mathrm{x}$ E. urophylla.

\begin{tabular}{|c|c|c|c|c|c|c|c|c|c|}
\hline \multirow{2}{*}{$\begin{array}{l}\text { Fontes de } \\
\text { Variação }\end{array}$} & \multirow[b]{2}{*}{ GL } & \multicolumn{8}{|c|}{ Quadrados Médios } \\
\hline & & $\begin{array}{c}\text { SOBCV } \\
(\%)\end{array}$ & $\begin{array}{c}\text { ENRCS } \\
(\%)\end{array}$ & $\begin{array}{c}\text { ALTCS } \\
(\mathrm{cm})\end{array}$ & $\begin{array}{c}\text { SOB50 } \\
\text { (\%) }\end{array}$ & $\begin{array}{l}\text { ALT50 } \\
(\mathrm{cm})\end{array}$ & $\begin{array}{l}\text { DC50 } \\
(\mathrm{mm})\end{array}$ & $\begin{array}{c}\text { PSPA } \\
\text { (g) }\end{array}$ & $\begin{array}{c}\text { PSR } \\
\text { (g) }\end{array}$ \\
\hline$\overline{\text { Clone (C) }}$ & 3 & $85,25^{\text {ns }}$ & $2736,61^{*}$ & $262,10^{*}$ & $5646,16^{*}$ & $303,08^{*}$ & $2,08^{*}$ & $20,16^{*}$ & $3,33^{*}$ \\
\hline Trat. (T) & 3 & $26,65^{\mathrm{ns}}$ & $321,25^{\mathrm{ns}}$ & $20,87^{\mathrm{ns}}$ & $1193,03^{*}$ & $29,83^{\mathrm{ns}}$ & $0,41^{\mathrm{ns}}$ & $3,10^{\mathrm{ns}}$ & $0,22^{\mathrm{ns}}$ \\
\hline $\mathrm{C} * \mathrm{~T}$ & 9 & $116,17^{*}$ & $140,04^{\mathrm{ns}}$ & $16,35^{\mathrm{ns}}$ & $258,25^{\text {ns }}$ & $21,57^{\mathrm{ns}}$ & $0,12^{\mathrm{ns}}$ & $1,57^{\mathrm{ns}}$ & $0,36^{*}$ \\
\hline Resíduo & 48 & 51,47 & 177,21 & 10,38 & 277,51 & 11,84 & 0,16 & 1,20 & 0,09 \\
\hline Média Geral & - & 94,2 & 80,9 & 13,3 & 65,2 & 18,2 & 2,2 & 3,8 & 1,3 \\
\hline $\mathrm{CV}_{\text {exp }}(\%)$ & - & 8,3 & 21,4 & 26,6 & 26,7 & 29,0 & 23,5 & 20,0 & 21,4 \\
\hline
\end{tabular}

Revista Árvore, Viçosa-MG, v.35, n.5, p.1017-1026, 2011 


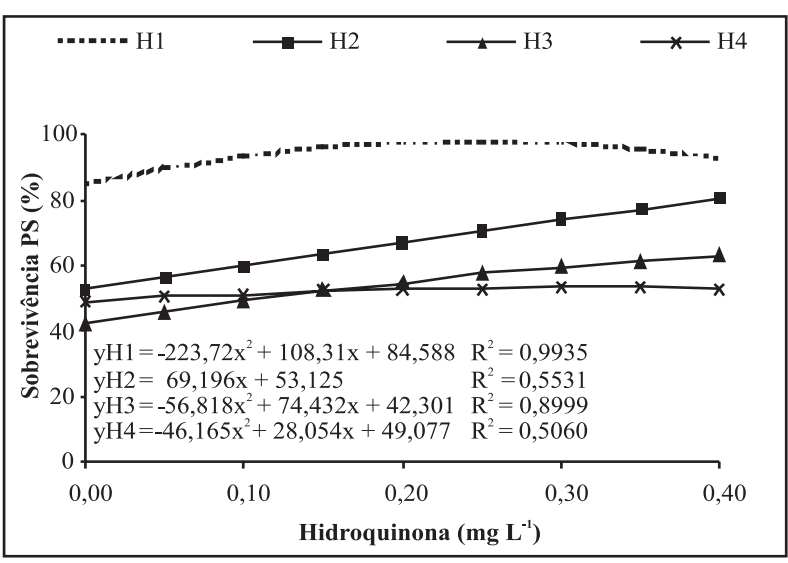

Figura 1 - Sobrevivência das miniestacas a pleno sol (PS), aos 50 dias de idade, em função da aplicação do cofator hidroquinona associado a $500 \mathrm{mg} \mathrm{L}^{-1} \mathrm{de}$ AIB, dos quatro clones de Eucalyptus grandis $\mathrm{x}$ E. urophylla.

Figure 1 - Survival under full sun of the mini-cuttings of four clones from Eucalyptus grandis $x$ E. urophylla 50 days after application of hydroquinone cofactor associated to $500 \mathrm{mg} \mathrm{L}^{-1}$ IBA.

sobrevivência na saída da casa de vegetação com a aplicação da concentração a partir de $0,2 \mathrm{mg} \mathrm{L}^{-1}$ de prolina.

Quanto ao enraizamento na saída da casa de sombra (Figura 2), todos os clones apresentaram a mesma tendência de comportamento encontrada na saída da casa de vegetação.
Quanto à altura das miniestacas na saída da casa de sombra (Figura 3), notou-se que, no clone H4, a aplicação de doses crescentes de prolina não influenciou significativamente no crescimento das miniestacas. Nos clones H1 e H3, a aplicação de doses a partir de $0,2 \mathrm{mg} \mathrm{L}^{-1}$ de prolina apresentaram os melhores resultados, já para o clone H2 a não aplicação de prolina exibiu os melhores índices de crescimento em altura das miniestacas na saída da casa de sombra. Da mesma forma, analisando a altura das miniestacas a pleno sol (Figura 3), observou-se que a tendência de comportamento dos clones estudados $(\mathrm{H} 1, \mathrm{H} 2, \mathrm{H} 3$ e H4) foi semelhante à verificada na saída da casa de sombra.

Em relação à sobrevivência das plantas a pleno sol (Figura 4), os clones H1, H2, H3 e H4 apresentaram comportamento semelhante ao observado na saída da casa de sombra. Os melhores resultados de sobrevivência das plantas a pleno sol foram obtidos nos clones H1 e $\mathrm{H} 4$ com doses de $0,4 \mathrm{mg} \mathrm{L}^{-1}$ de prolina e nos clones $\mathrm{H} 2$ e H3, com doses entre 0,2 e 0,4 $\mathrm{mg} \mathrm{L}^{-1}$ de prolina.

A hipótese era de que a aplicação de prolina associada ao AIB nas miniestacas promovia aumento nos índices de enraizamento, situação confirmada em todos os clones estudados. Resultados benéficos utilizando a prolina, associada ao AIB, foram encontrados por Lima (1998), que constatou que a adição deste cofator no meio de cultura aumentou o percentual de

Tabela 2 - Resultados da análise de variância das características de sobrevivência das miniestacas na saída da casa de vegetação (SOBCV); do percentual de enraizamento (ENRCS) e altura (ALTCS) das miniestacas na saída da casa de sombra; e da sobrevivência (SOB50), altura (ALT50), diâmetro de colo (DC50) e da massa de matéria seca da parte aérea (PSPA) e do sistema radicular (PSR) das plantas aos 50 dias de idade, em função das concentrações do cofator prolina associado a $500 \mathrm{mg} \mathrm{L}^{-1}$ de AIB, dos quatro clones de Eucalyptus grandis x E. urophylla.

Table 2 - Results of the Analysis of Variance (ANOVA) of survival data on minicuttings of four Eucalyptus grandis $x$ E. urophylla clones regarding greenhouse exit survival (GHES); shade house exit mini-cuttings rooting percentage (SHEMRP) and height (H); survival (SOB50), height (H50), root collar diameter (DC50) and dry mass of the aerial portion (DMAP) and root system (DMR) of the plants at 50 days of age, as a result of different concentrations of proline cofactor associated with $500 \mathrm{mg} \mathrm{L}^{-1} \mathrm{IBA}$.

\begin{tabular}{|c|c|c|c|c|c|c|c|c|c|}
\hline \multirow{2}{*}{$\begin{array}{l}\text { Fontes de } \\
\text { Variação }\end{array}$} & \multirow[b]{2}{*}{ GL } & \multicolumn{8}{|c|}{ Quadrados Médios } \\
\hline & & $\begin{array}{c}\text { SOBCV } \\
(\%)\end{array}$ & $\begin{array}{c}\text { ENRCS } \\
(\%)\end{array}$ & $\begin{array}{c}\text { ALTCS } \\
(\mathrm{cm})\end{array}$ & $\begin{array}{l}\text { SOB50 } \\
(\%)\end{array}$ & $\begin{array}{l}\text { ALT50 } \\
(\mathrm{cm})\end{array}$ & $\begin{array}{l}\text { DC50 } \\
(\mathrm{mm})\end{array}$ & $\begin{array}{c}\text { PSPA } \\
\text { (g) }\end{array}$ & $\begin{array}{c}\text { PSR } \\
(\mathrm{g})\end{array}$ \\
\hline$\overline{C l o n e}(\mathrm{C})$ & 3 & $501,91^{*}$ & $500,28^{*}$ & $501,39^{*}$ & $1071,78^{*}$ & $523,95^{*}$ & $1,52^{*}$ & $36,45^{*}$ & $2,12^{*}$ \\
\hline Trat. (T) & 3 & $1006,47^{*}$ & $1408,49^{*}$ & $30,23^{*}$ & $2445,48^{*}$ & $40,03^{*}$ & $0,16^{\mathrm{ns}}$ & $1,53^{\mathrm{ns}}$ & $0,35^{\mathrm{ns}}$ \\
\hline $\mathrm{C}^{*} \mathrm{~T}$ & 9 & $309,86^{*}$ & $256,14^{*}$ & $27,90^{*}$ & $209,69^{\mathrm{ns}}$ & $28,10^{*}$ & $0,22^{*}$ & $2,01^{\mathrm{ns}}$ & $0,36^{*}$ \\
\hline Resíduo & 48 & 96,23 & 116,98 & 6,04 & 262,45 & 7,70 & 0,10 & 1,01 & 0,17 \\
\hline Média Geral & - & 92,3 & 83,1 & 15,1 & 73,2 & 19,8 & 2,3 & 3,8 & 1,3 \\
\hline $\mathrm{CV}_{\exp }(\%)$ & - & 14,9 & 17,7 & 28,5 & 27,2 & 23,7 & 19,2 & 24,4 & 21,8 \\
\hline
\end{tabular}

“ns” e “*” = não-significativo e significativo, respectivamente, ao nível de 5\% de probabilidade, pelo teste de F.

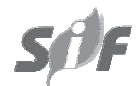

Revista Árvore, Viçosa-MG, v.35, n.5, p.1017-1026, 2011 

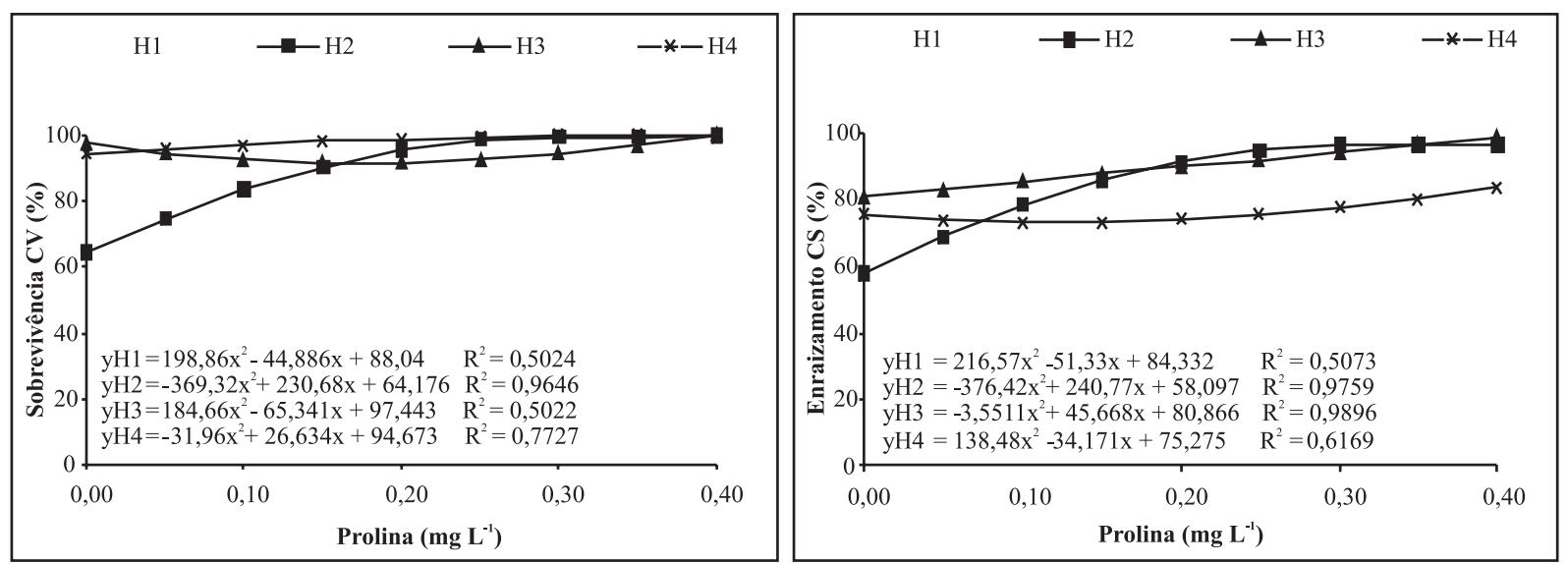

Figura 2 - Sobrevivência e enraizamento das miniestacas na saída da casa de vegetação (CV) e na saída da casa de sombra (CS), aos 25 e 35 dias de idade, respectivamente, em função da aplicação do cofator prolina a $500 \mathrm{mg} \mathrm{L}^{-1}$ de AIB, dos quatro clones de Eucalyptus grandis x E. urophylla.

Figure 2-Greenhouse exit and shade house exit rooting and survival of mini-cuttings of four Eucalyptus grandis $x$ E. urophylla clones, at 25 and 35 days of age, respectively, as a result of applications of proline cofactor at the $500 \mathrm{mg} \mathrm{L}^{-1} \mathrm{IBA}$.
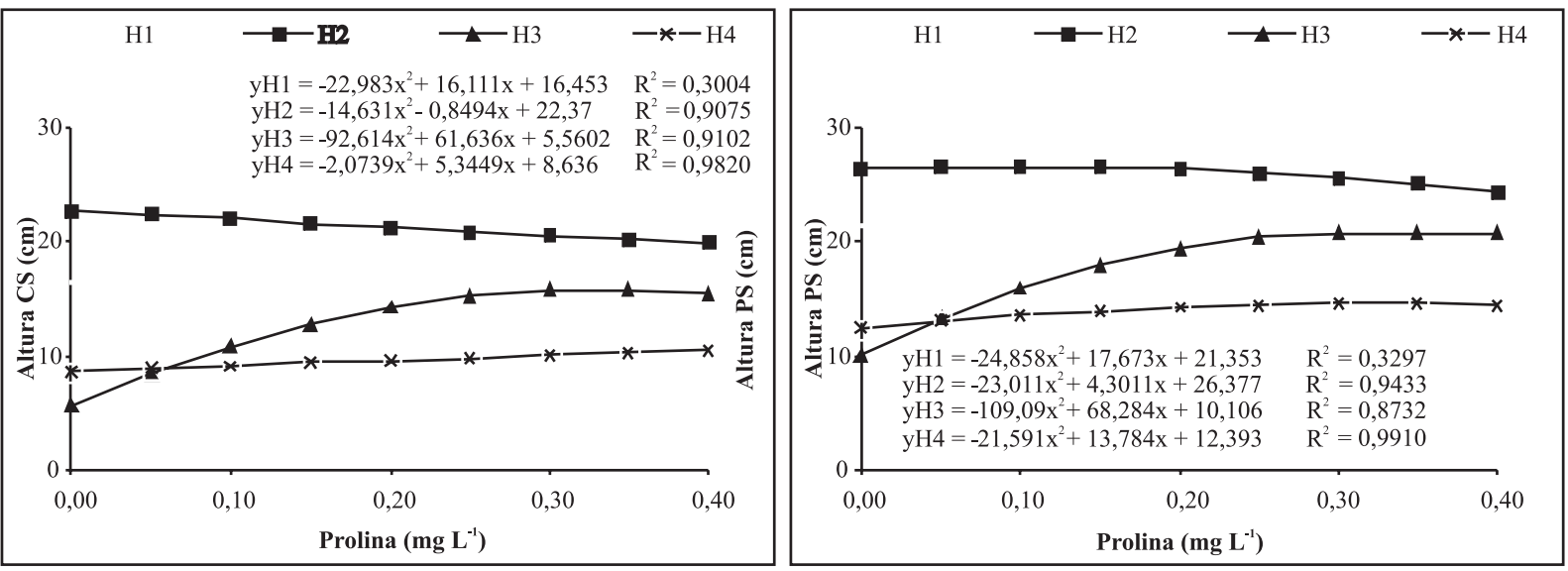

Figura 3 - Altura das miniestacas na saída da casa de sombra (CS) e a pleno sol (PS), aos 35 e 50 dias de idade, respectivamente, em função da aplicação do cofator prolina associado a $500 \mathrm{mg} \mathrm{L}^{-1}$ de AIB, dos quatro clones de Eucalyptus grandis x E. urophylla.

Figure 3 - Full sun and shade house exit height of mini-cuttings of four Eucalyptus grandis $x$ E. urophylla clones at 35 and 50 days of age, respectively, as a result of applications of proline cofactor associated with $500 \mathrm{mg} \mathrm{L}^{-1} \mathrm{IBA}$.

enraizamento de plântulas de Eucalyptus grandis. Já Camara et al. (2000) verificaram que a adição de prolina no meio de cultura favoreceu o crescimento de calos em tecidos da planta de milho. A prolina também aumentou a porcentagem de brotos enraizados e o número de raízes por brotos em Prumus avium e $P$. cerasus (ORLIKOWSKA, 1992).
Quando comparada com os outros cofatores estudados neste trabalho, as miniestacas tratadas com prolina foram superiores. Isso se deve ao fato de a prolina exercer importante papel de osmorregulador no metabolismo das plantas, juntamente com outros solutos (aminoácidos, açúcares, ácidos orgânicos e íons orgânicos). Esse cofator mantém o equilíbrio do potencial

Revista Árvore, Viçosa-MG, v.35, n.5, p.1017-1026, 2011 


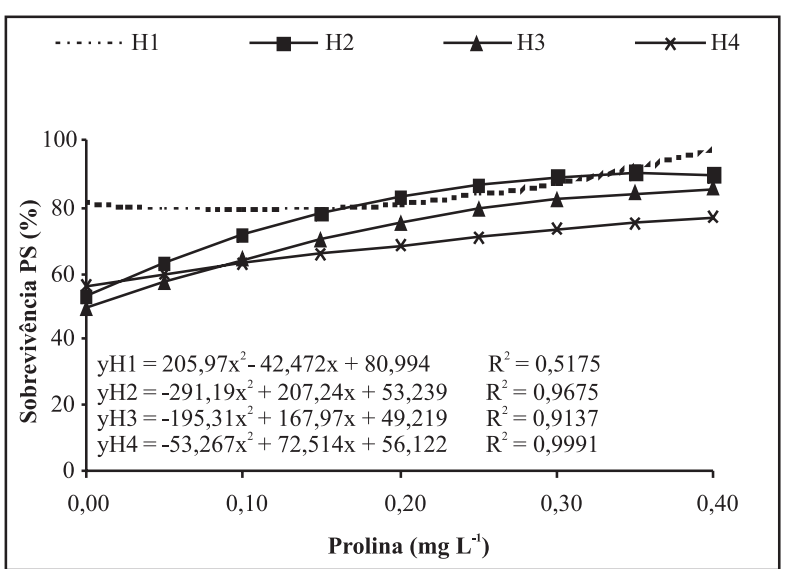

Figura 4 - Sobrevivência das miniestacas a pleno sol (PS), aos 50 dias de idade, em função da aplicação do cofator prolina associado a $500 \mathrm{mg} \mathrm{L}^{-1}$ de AIB, dos quatro clones de Eucalyptus grandis x E. urophylla.

Figure 4-Mini-cuttings of four Eucalyptus grandis $x$ E. urophylla clones survival in full sun, at 50 days of age, as a result of applications of proline cofactor associated with $500 \mathrm{mg} \mathrm{L}^{-1}$ IBA.

hídrico dentro da célula, possibilitando a continuação do alongamento celular, facilitando condutâncias estomáticas mais altas sob potenciais hídricos mais baixos, aumentando o turgor e mantendo o crescimento dos meristemas das raízes, indicando que o ajuste osmótico é uma aclimatação que aumenta a tolerância à desidratação (HARE; CRESS, 1997; TAIZ; ZEIGER, 2004).

\subsection{Eficiência do triptofano no enraizamento adventício}

Com base nos resultados da análise de variância das características avaliadas (Tabela 3), observou-se efeito significativo, pelo teste de F ( $P>0,05)$, da interação “clone x tratamento” sobre apenas uma das características avaliadas (ENRCS - percentual de enraizamento das miniestacas na saída da casa de sombra), indicando respostas diferenciadas dos clones em relação ao cofator e aos tratamentos adotados.

Os coeficientes de variação experimental encontrados variaram de 6,7 até 28,8\%, evidenciando-se razoável precisão experimental em relação às características estudadas, de acordo com os valores normalmente encontrados na literatura (RIBAS, 1997; WENDLING et al., 2000; TITON, 2001).

Não foram observadas diferenças estatísticas entre os tratamentos dos clones estudados em relação às características de sobrevivência das miniestacas na saída da casa de vegetação, diâmetro de colo e peso de massa de matéria seca da parte aérea e da raiz das plantas a pleno sol (Tabela 3).

Quanto ao enraizamento das miniestacas na saída da casa de sombra (Figura 5), os clones H2, H3 e H4 apresentaram comportamento semelhante entre si, sendo os melhores resultados de enraizamento das miniestacas na saída da casa de sombra obtidos com a aplicação de $0,80 \mathrm{mg} \mathrm{L}^{-1}$ de triptofano. Já para o clone H1, os resultados de sobrevivência na saída da casa de sombra indicaram efeito negativo com aplicação de triptofano.

Tabela 3 - Resultados da análise de variância das características de sobrevivência das miniestacas na saída da casa de vegetação (SOBCV); do percentual de enraizamento (ENRCS) e altura (ALTCS) das miniestacas na saída da casa de sombra; e da sobrevivência (SOB50), altura (ALT50), diâmetro de colo (DC50) e da massa de matéria seca da parte aérea (PSPA) e do sistema radicular (PSR) das plantas aos 50 dias de idade, em função das concentrações do cofator triptofano associado a $500 \mathrm{mg} \mathrm{L}^{-1}$ de AIB, dos quatro clones de Eucalyptus grandis x E. urophylla.

Table 3 - Results of the Analysis of Variance (ANOVA) of survival data on minicuttings of four Eucalyptus grandis $x$ E. urophylla clones regarding greenhouse exit survival (GHES); shade house exit mini-cuttings rooting percentage (SHRP) and height (HSH); survival (SUV50), height (H50), root collar diameter (DC50) and dry mass of the aerial portion (DMAP) and root system (DMRS) of the plants at 50 days of age, as a result of different concentrations of tryptophane cofactor associated with $500 \mathrm{mg} \mathrm{L}^{-1}$ IBA.

\begin{tabular}{|c|c|c|c|c|c|c|c|c|c|}
\hline \multirow{2}{*}{$\begin{array}{l}\text { Fontes de } \\
\text { Variação }\end{array}$} & \multirow[b]{2}{*}{ GL } & \multicolumn{8}{|c|}{ Quadrados Médios } \\
\hline & & $\begin{array}{c}\text { SOBCV } \\
(\%)\end{array}$ & $\begin{array}{c}\text { ENRCS } \\
(\%)\end{array}$ & $\begin{array}{l}\text { ALTCS } \\
(\mathrm{cm})\end{array}$ & $\begin{array}{c}\text { SOB50 } \\
(\%)\end{array}$ & $\begin{array}{l}\text { ALT50 } \\
(\mathrm{cm})\end{array}$ & $\begin{array}{l}\text { DC50 } \\
(\mathrm{mm})\end{array}$ & $\begin{array}{c}\text { PSPA } \\
\text { (g) }\end{array}$ & $\begin{array}{c}\text { PSR } \\
\text { (g) }\end{array}$ \\
\hline Clone (C) & 3 & $13,83^{\text {ns }}$ & $77,11^{\mathrm{ns}}$ & $137,27^{*}$ & $387,98^{*}$ & $138,78^{*}$ & $0,43^{*}$ & $4,75^{*}$ & $0,31^{*}$ \\
\hline Trat. (T) & 3 & $88,70^{\mathrm{ns}}$ & $221,96^{*}$ & $33,13^{*}$ & $475,87^{*}$ & $41,50^{*}$ & $0,01^{\mathrm{ns}}$ & $4,37^{\mathrm{ns}}$ & $0,14^{\mathrm{ns}}$ \\
\hline $\mathrm{C}^{*} \mathrm{~T}$ & 9 & $56,69^{\mathrm{ns}}$ & $97,18^{*}$ & $9,72^{\text {ns }}$ & $182,90^{\mathrm{ns}}$ & $11,27^{\mathrm{ns}}$ & $0,05^{\mathrm{ns}}$ & $1,03^{\text {ns }}$ & $0,08^{\text {ns }}$ \\
\hline Resíduo & 48 & 37,03 & 42,52 & 8,09 & 109,25 & 8,19 & 0,07 & 1,17 & 0,10 \\
\hline Média Geral & - & 95,9 & 90,1 & 13,7 & 83,5 & 18,8 & 2,1 & 3,6 & 1,2 \\
\hline $\mathrm{CV}_{\exp }(\%)$ & - & 6,7 & 8,6 & 28,8 & 14,7 & 21,6 & 13,6 & 23,5 & 28,1 \\
\hline
\end{tabular}

“ns” $\mathrm{e}^{\text {“*” }}=$ não-significativo e significativo, respectivamente, a 5\%, pelo teste de F.

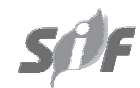

Revista Árvore, Viçosa-MG, v.35, n.5, p.1017-1026, 2011 
Os resultados de sobrevivência das miniestacas a pleno sol (Figura 5) foram semelhantes aos encontrados no enraizamento das miniestacas na saída da casa de sombra, e os clones H2, H3 e H4 apresentaram melhores índices de sobrevivência a pleno sol com a aplicação de $0,8 \mathrm{mg} \mathrm{L}^{-1}$ de triptofano. O clone $\mathrm{H} 1$ não apresentou efeito significativo com a aplicação de triptofano.
Com relação à altura das miniestacas na saída da casa de sombra e a pleno sol (Figura 6), observou-se, para o clone H2, que a aplicação de triptofano apresentou efeito negativo sobre essas características, enquanto as respostas obtidas para os clones $\mathrm{H} 2, \mathrm{H} 3$ e H4, de modo geral, mostraram que estes foram indiferentes à aplicação de triptofano.
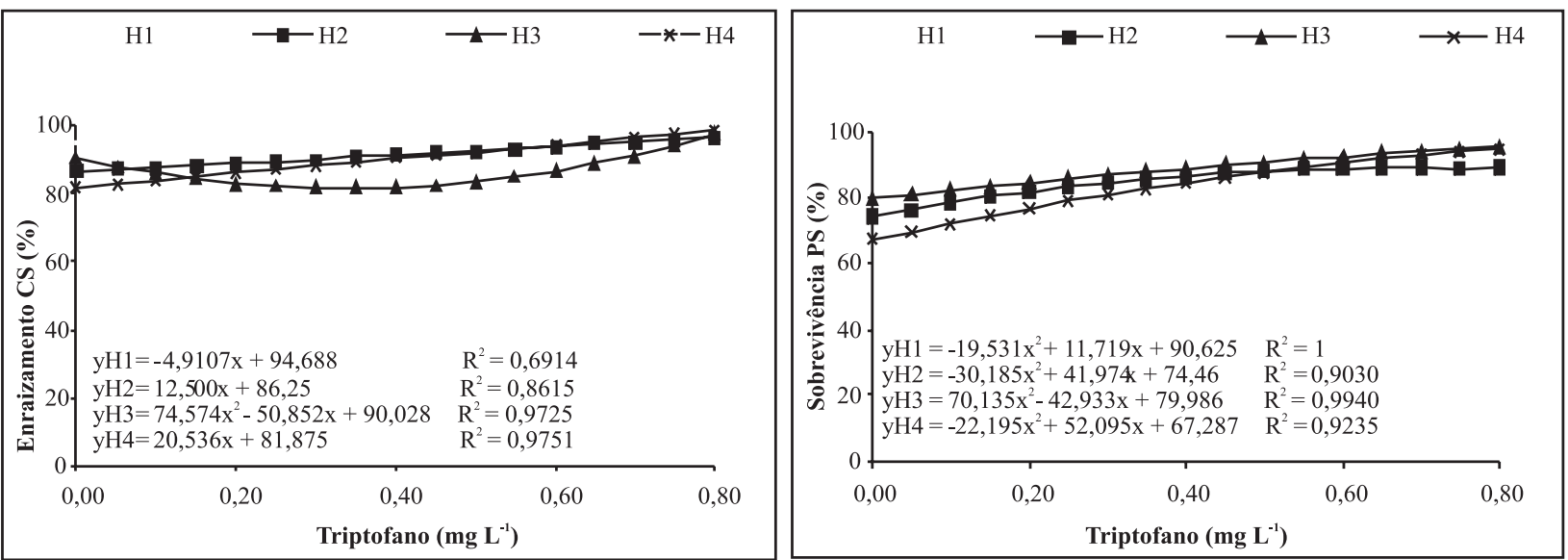

Figura 5 - Enraizamento e sobrevivência das miniestacas na saída da casa de vegetação (CV) e a pleno sol (PS), aos 35 e 50 dias de idade, respectivamente, em função da aplicação do cofator triptofano associado a $500 \mathrm{mg} \mathrm{L}^{-1} \mathrm{de}$ AIB, dos quatro clones de Eucalyptus grandis x E. urophylla.

Figure 5 - Mini-cuttings of four Eucalyptus grandis $x$ E. urophylla clones in full sun and greenhouse exit rooting and survival, at 35 and 50 days of age, respectively, as a result of applications of tryptophane cofactor associated with $500 \mathrm{mg} \mathrm{L}^{-1} \mathrm{IBA}$.
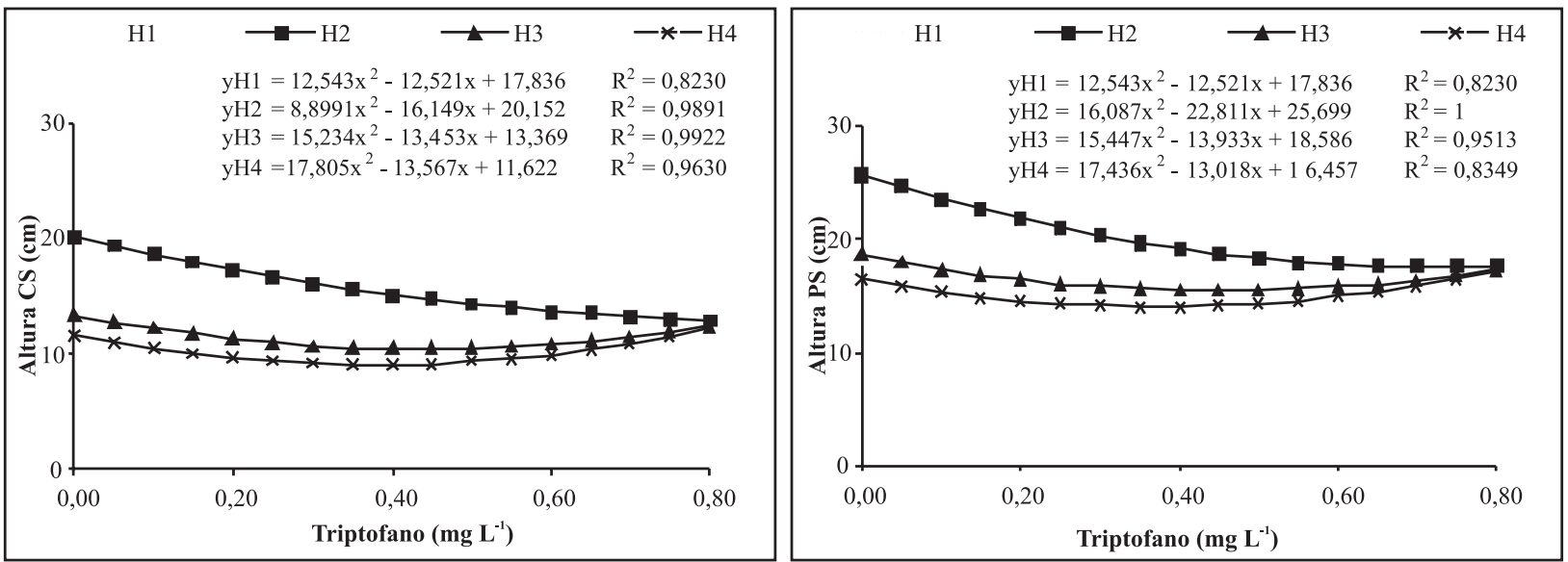

Figura 6 - Altura das miniestacas na saída da casa de sombra (CS) e a pleno sol (PS), aos 35 e 50 dias de idade, respectivamente, em função da aplicação do cofator triptofano associado a $500 \mathrm{mg} \mathrm{L}^{-1}$ de AIB, dos quatro clones de Eucalyptus grandis x E. urophylla.

Figure 6 - Mini-cuttings of four Eucalyptus grandis $x$ E. urophylla clones shade house exit and in full sun height, at 35 and 50 days of age, respectively, as a result of applications of tryptophane cofactor associated with $500 \mathrm{mg}$ $L^{-1} I B A$.

Revista Árvore, Viçosa-MG, v.35, n.5, p.1017-1026, 2011 
A hipótese era de que a aplicação de triptofano associado com AIB promovia aumento nos índices de enraizamento e sobrevivência das miniestacas, principalmente nos clones com menores percentuais de enraizamento. De certa forma, esse fato foi confirmado em três dos quatro clones estudados. Acredita-se que as respostas superiores dos tratamentos que utilizaram esse aminoácido se devem ao fato de que as plantas convertem triptofano em AIA (ácido indolacético), através de várias rotas metabólicas. Tal conversão é importante para no início do desenvolvimento e estabelecimento do eixo raiz-parte aérea das plantas (TAIZ; ZEIGER, 2004).

Conforme alguns autores, o nível de triptofano nas células das plantas é controlado pela sua própria concentração que existe nas células, que será provavelmente transformado em auxinas (WILDHOLM, 1971, citado por DUTRA et al., 2002). Além disso, há uma correlação positiva entre o nível de auxinas e a porcentagem de enraizamento. Assim, quando o nível endógeno de auxinas é elevado, há maior porcentagem de enraizamento adventício (GASPAR et al., 1988, citados por DUTRA et al., 2002). Não obstante, Lima (1998) verificou que o triptofano não influenciou o percentual de enraizamento, apresentando, entretanto, efeito positivo no número de raízes das plântulas de Eucalyptus grandis. Orlikowska (1992) também relatou aumento no número de raízes em estacas de macieira ao utilizar alguns aminoácidos, dentre eles o triptofano.

\section{CONCLUSÕES}

Com base nos resultados obtidos, conclui-se que:

- Os cofatores triptofano $\left(0,8 \mathrm{mg} \mathrm{L}^{-1}\right)$ e a hidroquinona ( 0,2 a $\left.0,4 \mathrm{mg} \mathrm{L}^{-1}\right)$, aplicado associado ao AIB, promoveram aumento nos índices de enraizamento das miniestacas em três dos quatro clones avaliados.

- A aplicação de prolina (0,2 a 0,4 mg L $\left.\mathrm{m}^{-1}\right)$, associada ao AIB, promoveu melhoria expressiva no enraizamento das miniestacas nos quatros clones estudados, evidenciando ser entre os cofatores testados o mais eficiente.

\section{AGRADECIMENTOS}

À International Paper do Brasil, pela oportunidade de realização deste trabalho, pela disponibilização do material genético (clones) e pelo apoio financeiro e de infraestrutura.

\section{REFERÊNCIAS}

ALFENAS, A. C. et al. Clonagem e doenças do eucalipto. Viçosa, MG: Universidade Federal de Viçosa, 2009. 500p.

CAMARA, T. R. et al. Efeito do estresse salino e da prolina exógena em calos de milho. Revista Brasileira de Fisiologia Vegetal, v.12, n.2, p.146-155, 2000.

DUTRA, L. F.; KERSTEN, E.; FACHINELLO, J. C. Época de coleta, ácido indolbutírico e triptofano no enraizamento de estacas de pessegueiro.

Scientia Agricola, v.59, n. 2, p.327-333, 2002.

HACKETT, W. P. Donor plant maturation and adventitious root formation. In: DAVIES, T. D.; HAISSIG, B. E.; SANKHLA, N. Adventitious root formation in cuttings. Portland: Dioscorides Press, 1987. p.11-28.

HAGGQUIST, M. L. et al. Identification of tryptophan in leachate of oat hulls (Avena sativa) as mediator of root growth regulation. Physiologia Plantarum, v.72, p.423-427, 1988.

HARE, P. D.; CRESS, W. A. Metabolic implications of stress-induced proline accumulation in plants. Plant Growth

Regulation, v.21, n.1, p.79-102, 1997.

LIMA, C. C. M. Uso de aditivos e cofatores na rizogênese de plântulas de Eucalyptus grandis Hill in vitro. 1998. $99 \mathrm{f}$. Dissertação (Mestrado em Ciências Florestais) Escola Superior de Agricultura Luiz de Queiroz, Piracicaba, 1998.

NORBERTO, P. M. Efeitos da época de poda, cianamida hidrogenada, irrigação e ácido indolbutírico na colheita antecipada e enraizamento de estacas de figueira (Ficus carica L.). 1999. 89f. Dissertação (Mestrado em Agronomia - Fitotecnia) Universidade Federal de Lavras, Lavras, 1999.

ONO, E. O.; RODRIGUES, J. D. Aspectos da fisiologia do enraizamento de estacas caulinares. Jaboticabal: Funep, 1996. 81p. 
ORLIKOWSKA, T. Influence of arginine on in vitro rooting of dwarf apple rootstock. Plant Cell Tissue and Organ Culture, v.31, n.1, p.9-14, 1992.

RIBAS, K. C. Interações entre auxina e cofatores do enraizamento na promoção do sistema radicular em estacas de Eucalyptus grandis W. Hill ex Maiden. 1997. 150f. Tese (Doutorado em

Ciências Biológicas) - Universidade Estadual de São Paulo, Botucatu, 1997.

TAIZ, L.; ZEIGER, E. Fisiologia vegetal. Porto Alegre: Artmed, 2004. 719p. (Tradução).
TITON, M. Propagação clonal de Eucalyptus grandis por miniestaquia e microestaquia. 2001. 65f. Dissertação

(Mestrado em Ciência Florestal) - Universidade Federal de Viçosa, Viçosa, MG, 2001.

WENDLING, I. et al. Propagação clonal de híbridos de Eucalyptus spp. por miniestaquia. Revista Árvore, v.24, n.2, p.181-186, 2000.

XAVIER, A.; WENDLING, I.; SILVA, R. L.

Silvicultura clonal: princípios e técnicas Viçosa, MG: Universidade Federal de Viçosa, 2009. 272p. 